\title{
Upper Gastrointestinal Bleeding Secondary to an Incidental, Impacted Foreign Body in the Duodenum
}

\author{
Emuobor Odeghe ${ }^{1}$, Azeberoje Osueni ${ }^{2}$, Opeyemi O. Owoseni ${ }^{3}$, Funmi Adeniyi Sr. ${ }^{4,5}$, Olufunmilayo Lesi 6 \\ 1. Gastroenterology, University of Lagos and Lagos University Teaching Hospital, Lagos, NGA 2. Medicine, Brookdale \\ University Hospital and Medical Center, Brooklyn, USA 3. Gastroenterology, Federal Medical Center, Abeokuta, NGA 4. \\ Pediatrics/Gastroenterology, College of Medicine, University of Lagos, Lagos, NGA 5. Pediatrics/Gastroenterology, \\ Lagos University Teaching Hospital, Lagos, NGA 6. Gastroenterology, Lagos University Teaching Hospital, Lagos, NGA
}

Corresponding author: Azeberoje Osueni, a.osueni@gmail.com

\begin{abstract}
A 68-year-old woman presented with a three-week history of upper abdominal discomfort, vomiting of coffee ground substance, and passage of tarry stools. There were no typical risk factors for gastroduodenal or liver disease. Gastroscopy done showed a fishbone impacted in the wall of the pyloric opening with its free end abutting on the wall of the duodenum resulting in a duodenal ulcer. Antral erosions were also noted. Retrieval forceps were used to retrieve the fishbone. The patient did not remember eating any fish containing meal, and there was no odynophagia. This case emphasizes the importance of considering foreign bodies as a cause of upper gastrointestinal bleeding as well as the need for an endoscopic review of all patients with upper gastrointestinal bleed.
\end{abstract}

Categories: Internal Medicine, Gastroenterology, Epidemiology/Public Health

Keywords: endoscopy, foreign body, upper gastrointestinal bleeding, duodenum, stomach, melena, ulceration

\section{Introduction}

Ingestion of foreign bodies that lodge in the upper gastrointestinal tract is common. Most objects can pass through the gastrointestinal tract spontaneously [1]. Approximately $80 \%$ of ingested foreign bodies that reach the stomach will pass through the gastrointestinal tract uneventfully, while the remaining $20 \%$ may cause complications such as obstruction, perforation, or hemorrhage [2]. We report the case of a 68-year-old woman who presented with upper abdominal discomfort, two episodes of vomiting of coffee grounds, and passage of dark, tarry stools, which were later found to be due to upper gastrointestinal bleeding from an incidental, impacted foreign body in the duodenum.

Received 01/17/2020 Review began 02/07/2020 Review ended 02/11/2020 Published 02/12/2020

๑) Copyright 2020 Odeghe et al. This is an open access article distributed under the terms of the Creative Commons Attribution License CC-BY 4.0., which permits unrestricted use, distribution, and reproduction in any medium, provided the original author and source are credited.

\section{Case Presentation}

A 68-year-old woman presented with a three-week history of upper abdominal discomfort, two episodes of coffee-ground emesis, and passage of dark, tarry stools. She did not take alcohol, non-steroidal antiinflammatory drugs, or herbal concoctions. She had no history of heartburn, regurgitation, or any problems with swallowing. She had no previous diagnosis of liver disease and no symptoms suggestive of liver disease. Examination revealed an elderly woman, who was in no respiratory distress. She was generally well looking and not pale, also did not have jaundice. Vitals signs were normal. On abdominal examination, there was mild tenderness in the epigastrium; otherwise, it was unremarkable. Rectal examination revealed the presence of black tarry stool. Examination of the cardiovascular, respiratory, and nervous systems was unremarkable. She was mildly anemic with a hemoglobin of $9.2 \mathrm{~g} / \mathrm{dL}$, and other laboratory tests were within normal limits. The patient had an upper gastrointestinal endoscopy showing areas of petechial hemorrhage in the stomach. A foreign body (later identified as a $2.5 \mathrm{~cm}$ long fishbone) was found in the first part of the duodenum with one end embedded in the wall, and the other end abutting the opposite wall of the duodenum. The free end had produced a $2 \mathrm{~cm}$ long ulcer on the opposite wall. This ulcer most likely bled due to peristaltic contractions as the sharp end of the foreign body caused more damage (Figures 1,2). 


\section{Cureus}

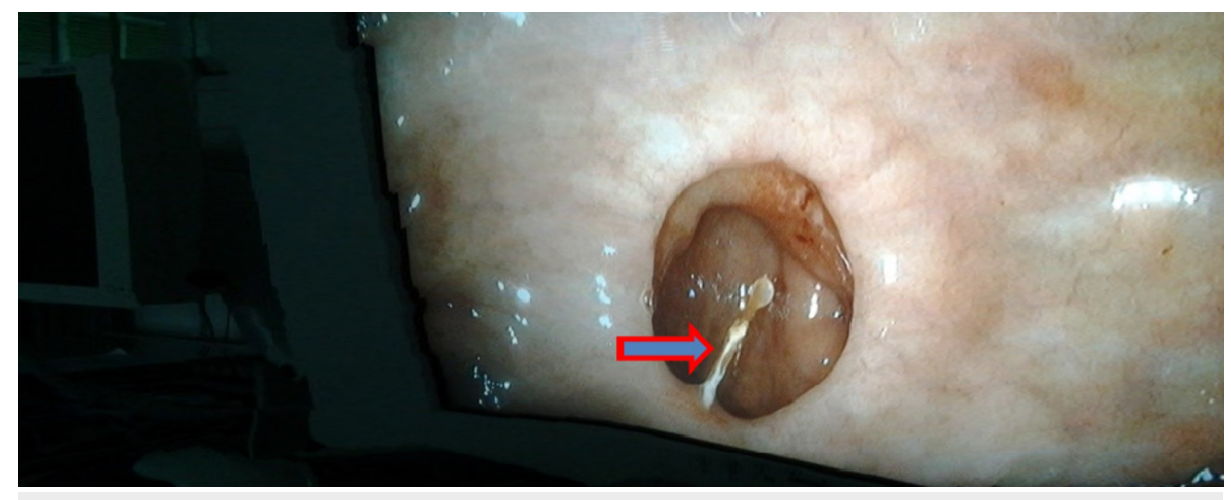

FIGURE 1: Endoscopic image showing the fishbone in the first part of the duodenum, with one end embedded in the wall and the other end abutting the opposite wall of the duodenum.

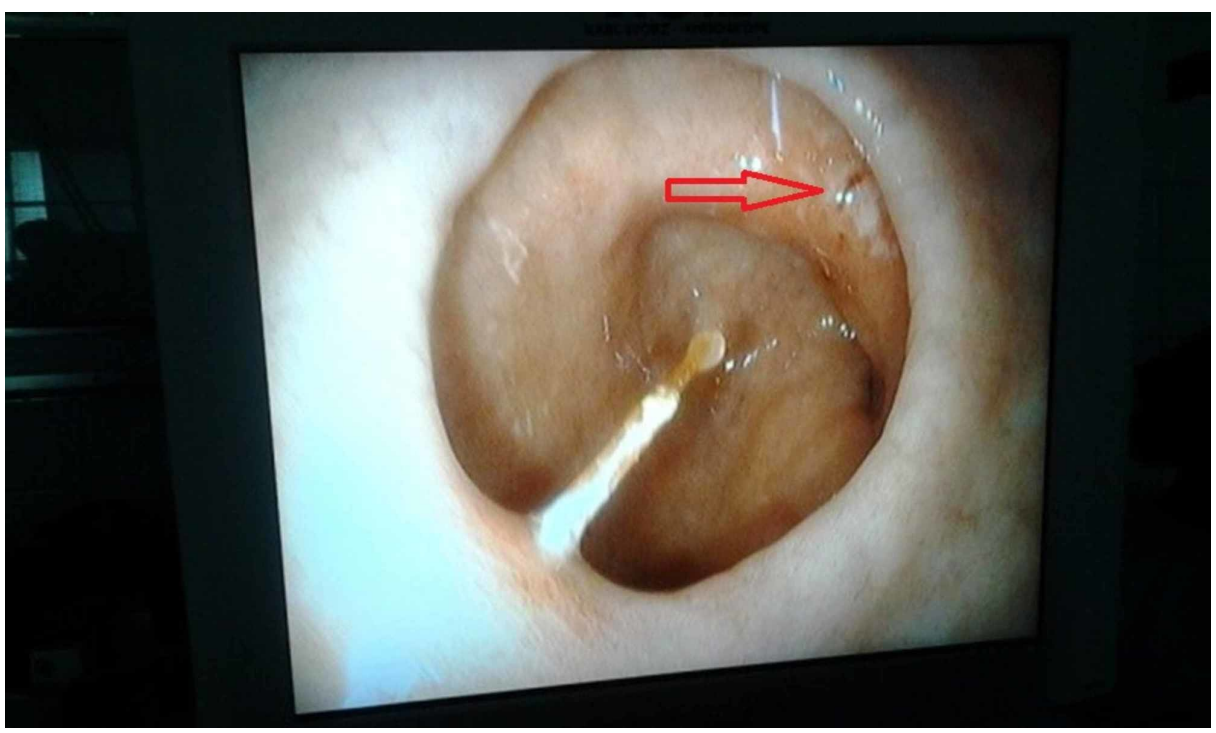

FIGURE 2: Image showing an ulcer in the first part of the duodenum caused by the fishbone.

Retrieval forceps were used to successfully remove the embedded foreign body. On further questioning, the patient did not remember when she last ate a fish containing meal.

\section{Discussion}

Ingestion of foreign bodies is common in clinical practice. Most objects pass through the gastrointestinal tract spontaneously, but some need endoscopic or surgical removal [3-5]. Factors that predispose to foreign body ingestion include male gender, alcohol or illicit drug use, use of dental prostheses, neuromuscular diseases, psychiatric illnesses, feeding disorders, and individuals in custody of prisons or orphanages $[3,6]$. The following gastrointestinal diseases may predispose to the presence of foreign bodies in the gastrointestinal tract: esophageal carcinoma, strictures, nutcracker esophagus, diverticulum, postgastrectomy, hiatus hernia, and achalasia $[7,8]$. The commonly encountered foreign bodies in adults include food boluses and pieces of food, fishbones, chicken bones, coins, and dental prostheses [7,9]. Sometimes, the offending object appears extremely unlikely such as guitarist pick and cat whisker $[10,11]$.

It is vital to obtain an accurate history of the timing, type of ingested object, and onset of symptoms. Symptoms may include retrosternal discomfort, odynophagia, dysphagia, melena, hematemesis, and fatigue [12-17]. Patients may not remember when the foreign body was ingested, as in this patient, and this may delay diagnosis $[18,19]$. Time from the ingestion of the foreign body to the onset of symptoms may vary from days to weeks $[4,5,12,18,19]$. The risk of retention and subsequent perforation or ulceration by these ingested objects depends on the nature of the foreign body (sharp or blunt) as well as the anatomical variations in the gastrointestinal tract with congenital, physiological narrowing or angulations, and previous 
surgery increasing these risks [20].

Complications that may occur from the presence of foreign bodies in the upper gastrointestinal tract include perforation, ulcerations, upper gastrointestinal bleeding, retroperitoneal hemorrhage, peritonitis, and intraabdominal abscess $[4,12,14-20]$. Our patient developed both ulceration and upper gastrointestinal bleeding. Management includes endoscopic retrieval of the object or surgical removal [7,13]. If bleeding is encountered during endoscopic removal of sharp/pointed objects, timely and meticulous resuscitation should be started with appropriate treatment (injection of adrenaline) if required at the bleeding point. A psychological evaluation may be necessary when the ingestion of a foreign body was intentional or in patients with suspected psychiatric illnesses or dementia [20].

\section{Conclusions}

We present a rare case of unremembered foreign body (fishbone) ingestion causing upper gastrointestinal bleeding in a 68-year-old female. Clinicians must consider foreign bodies as a cause of upper gastrointestinal bleeding even though it is not present in the history provided by the patient. Endoscopic evaluation and subsequent retrieval of the foreign body may be required to prevent complications.

\section{Additional Information \\ Disclosures}

Human subjects: Consent was obtained by all participants in this study. Conflicts of interest: In compliance with the ICMJE uniform disclosure form, all authors declare the following: Payment/services info: All authors have declared that no financial support was received from any organization for the submitted work. Financial relationships: All authors have declared that they have no financial relationships at present or within the previous three years with any organizations that might have an interest in the submitted work. Other relationships: All authors have declared that there are no other relationships or activities that could appear to have influenced the submitted work.

\section{References}

1. Quan-Peng L, Xian-Xiu G, Guo-Zhong J, et al.: Endoscopic retrieval of 28 foreign bodies in a 100-year-old female after attempted suicide. World J Gastroenterol. 2013, 19:4091-4093. 10.3748/wjg.v19.i25.4091

2. Henderson CT, Engel J, Schlesinger P: Foreign body ingestion: review and suggested guidelines for management. Endosc. 1987, 19:68-71. 10.1055/s-2007-1018238

3. Velitchkov NG, Grigorov GI, Losanoff JE, Kjossev KT: Ingested foreign bodies of the gastrointestinal tract: a retrospective analysis of 542 cases. World J Surg. 1996, 20:1001-1005. 10.1007/s002689900152

4. Karcz WK, Kulemann B, Seifert GJ, et al.: Video: Laparoscopic extirpation of a fork from the duodenum . Surg Endosc. 2011, 25:2363.

5. Sheu BS, Shin JS, Chen KW, Lin XZ, Lin CY: Endoscopic removal of a large intragastric foreign body with an overtube: a case report. Zhonghua Yi Xue Za Zhi. 1994, 54:193-197.

6. Arango LA, Sierra LP, Gutiérrez DC, Grisales MJ: Incidental foreign body in the gastrointestinal tract. Report of three cases and literature review. Rev Col Gastroenterol. 2011, 26:308-318.

7. Li Z, Sun Z, Zou D, Xu G, Wu R, Liao Z: Endoscopic management of foreign bodies in the upper GI tract: experience with 1088 cases in China. Gastrointest Endosc. 2006, 64:485-492. 10.1016/j.gie.2006.01.059

8. Chae HS, Lee TK, Kim YW, et al.: Two cases of steakhouse syndrome associated with nutcracker esophagus . Dis Esophag. 2002, 15:330-333. 10.1046/j.1442-2050.2002.00271.x

9. Zhang S, Cui Y, Gong X, Gu F, Chen M: Endoscopic management of the foreign bodies in the upper gastrointestinal tract in South China: a retrospective study of 561 cases. Dig Dis Sci. 2009, 55:1305-1312. 10.1007/s10620-009-0900-7

10. Lambrou, T, Khullar, V. , Rampertab, D and Cabrera, R.: Guitarist Pick for Melena: A Unique Case of an Upper GI Bleed.. International Journal of Clinical Medicine. 2017, 8:514-518. 10.4236/ijcm.2017.88048

11. Barranco R, Tacchella T, Pinto SL, Bonsignore A, Ventura F: An unusual and fatal case of upper gastrointestinal perforation and bleeding secondary to foreign body ingestion. J Forensic Leg Med. 2016, 41:72-75.

12. Chiu HH, Li JH, Chen JS: Penetration of esophageal wall by a fish bone . J Intern Med Taiwan. 2006, 17:298301.

13. Akenroye MI, Osukoya AT: Uncommon, undeclared oesophageal foreign bodies. Niger J Clin Pract. 2012, 15:244-246. 10.4103/1119-3077.97339

14. Lu YP, Yao M, Zhou XY, et al.: False esophageal hiatus hernia caused by a foreign body: a fatal event . World J Gastroenterol. 2014, 21:14510-14514. 10.3748/wjg.v20.i39.14510

15. Paulsen JM, Aragon GC, Jager DL, Borum ML: Unusual cause of upper gastrointestinal bleed: gastric ulceration and bleed secondary to ingested dental bridge. Am J Gastroenterol. 2009, 104:535-537. 10.1038/ajg.2008.83

16. Syrakos T, Zacharakis E, Antonitsis P, et al.: Surgical intervention for gastrointestinal foreign bodies in adults: a case series. Med Princ Pract. 2008, 17:276-279. 10.1159/000129605

17. Shatnawi NJ, Bani-Hani KE: Ingested chicken bone leading to aorto-esophageal fistula . Saudi Med J. 2005, 26:1442-1444.

18. Matrella F, Lhuaire M, Piardi T, et al.: Liver hilar abscesses secondary to gastrointestinal perforation by ingested fish bones: surgical management of two cases. Hepatobiliary Surg Nutr. 2014, 3:156-162. 10.3978/j.issn.2304-3881.2014.04.01 


\section{Cureus}

19. Lee MK, Hyun YK, Kim YJ, et al.: Retroperitoneal hemorrhage after endoscopic removal of a fish bone stuck in the duodenum of a patient receiving hemodialysis. Korean J Gastroenterol. 2011, 58:212-216.

10.4166/kjg.2011.58.4.212

20. Obinwa O, Cooper D, O'Riordan JM, Neary P: Gastrointestinal foreign bodies. Actual Problems of Emergency Abdominal Surgery. Dmitry Garbuzenko (ed): IntechOpen, London; 2016. 